\title{
EDITORIAL
}

\section{Delivering effective asthma care - how do we implement asthma guidelines?}

\author{
M.R. Partridge, L.M. Fabbri, K.F. Chung
}

Over the last 10 yrs there has been a burgeoning increase in asthma guidelines, initially concerning paediatric asthma [1], and subsequently all aspects of asthma for all ages and for all countries. Some have been produced nationally [2], some internationally [3], some adapted from global strategies and others produced specifically for developing countries. The Global Initiative for Asthma (GINA) guidelines [4] have now been translated into numerous languages. Most of the producers of these guidelines are now busy updating the guidelines in an evidence based manner involving systematic reviews undertaken in a variety of ways. In some countries the guidelines will only be endorsed by the state Health Care system if they have been produced in a certain manner.

Whilst it is correct that guidelines are as far as possible evidence based, and that the process of production is seen to be independent and scientifically rigorous, the available effort must not be expended solely on production. Equal attention needs to be paid to the dissemination and implementation of guidelines. Recent studies have shown that these aspects are not always well performed [5].

To address these issues the European Respiratory Society (ERS), European Academy of Allergy and Clinical Immunology (EAACI), and GINA devoted one day prior to the Madrid (Spain) 1999 ERS meeting to inform pulmonologists, primary care physicians, allergists and paediatricians of strategies that may alter health professional behaviour and improve asthma care. Invited delegates from 29 European countries debated the issue with the aim of taking back to their own countries effective strategies to better disseminate and implement asthma guidelines.

L. Fabbri addressed the issue of the production of guidelines and outlined how the current GINA guidelines had been produced, reviewed and revised, and explained the methodology currently being used to extensively revise these guidelines utilizing systematic reviews, information technologists, Website discussion groups and wide consultation. The first group of important areas for review being: when should long-term control asthma therapy be started? Are chronic steroids useful for children with only mild asthma? Does the use of peak flow meters improve the outcome of asthma care "outcomes", including reduced urgent care visits to physician or emergency room, hospitalizations, missed work or school days, symptom scores,

Chest Clinic, Whipps Cross Hospital, London, UK.

Correspondence: M.R. Partridge, Chest Clinic, Whipps Cross Hospital, Whipps Cross Road, London, E11 1NR, UK. Fax: 442085356709. or limitations to activity? Are there populations or settings in which peak flow monitoring is most beneficial (for example, are patients with mild, moderate or severe asthma more likely to benefit from peak flow monitoring?)? Do patient outcomes improve with use of peak flow monitoring during acute asthma exacerbations? Do patient outcomes improve with use of peak flow monitoring on a routine basis to monitor chronic, persistent asthma? What peak flow monitoring schedule is most effective (e.g. measurements twice or once a day? Periodic short term 2 week monitoring versus daily long term monitoring?)? What is the evidence that written asthma management plans (either daily asthma management plans or action plans to handle exacerbations) improve patient outcomes ("outcomes including reduced urgent care visits, missed work or school days, limitations to activity, symptom scores)? What are the relative impacts of action plans based on symptoms versus peak flow measurements? What is the role of antibiotics in the care of children and adults with an acute exacerbation of asthma? What is the evidence for the safety and efficacy of long-term therapies in infants and prepubertal children? What is the effect of long-term therapies on growth? What are the comparative and relative benefits of different therapies added to inhaled corticosteroids in treating patients with moderate and severe asthma?

These reviews are being undertaken as a joint initia- tive with the National Asthma Education Program (NAEP)/ GINA Science Base Committee, and serve as an example of the co-operation which will be necessary to reduce the costs of systematic reviews. The Committee will work with a professional agency to investigate these questions, and will perform the evidence based analysis that will provide the background for the report and for the evidence statements and recommendations of the Science Base Committee. Report, statements and recommendations will be posted in the GINA Website (www.ginasthma.com). In addition to this ambitious plan of continuous review and update of the GINA guidelines, members of the GINA Executive Committee and Advisory Board will review the 1995 Workshop Report [4] and update it in a publication that should be ready within 2 yrs.

M.R. Partridge addressed the issue of dissemination; a process designed to inform health professionals regarding the presence of guidelines and to ensure their knowledge and understanding of the content of the guidelines, a process essential to subsequent implementation but unlikely by itself to lead to any significant change in medical practice. Dissemination strategies can involve publication of 
guidelines in professional journals, postal distribution to relevant groups, incorporation of guidelines into continuing medical education programmes and specific educational initiatives focusing specifically on guidelines. M.R. Partridge described an extensive and costly British dissemination programme involving repeat mailings, specific educational meetings regarding the content of a guidelines revision, the breaking down of complex guidelines into key messages and the use of lay and medical press coupled with the easy availability of summary charts for use in the work place. Published evaluation of this dissemination strategy [6] confirmed its effectiveness in increasing awareness of guidelines, but key messages regarding specific medication were seemingly transmitted more successfully than those regarding correct diagnosis or the teaching of self-management skills.

Production and dissemination of guidelines are thus essential building blocks but it is their implementation, "... the turning of change in attitude and knowledge into change in medical practice..." [7], that is of most importance. C. Griffiths reviewed this subject and addressed understanding of behaviour change theories and results of studies on implementation in a variety of fields. Generally effective were strategies which involved multiple methods, decision support systems and interactive education. In the stages of change model it was made clear that different interventions are needed according to whether the health professional was in the precontemplative or contemplative stages (where information was needed), the preparation for change stage (education needed), action stage (decision support needed) or in the maintenance phase where audit and feedback were required. C. Griffiths emphasized the benefit of seeking the help of an experienced educationalist when designing clinician educational sessions [8] and referred extensively to reviews on this subject, (Cochrane Library: http://www.updatesoftware.com/clibhome/clib.htm and the Cochrane Effective Practice and Organisation of Care Group: http:// www.abdn.ac.uk/public_health/hsm/epoc) and quoted R. Grol in saying that "...evidence based practice needed evidence based implementation.".

Following these overviews on production, dissemination and implementation, the audience were informed by L. Laitinen of experience with the Finnish National Program, a $10 \mathrm{yr}$ programme now reaching the $5 \mathrm{yr}$ evaluation stage. Strict targets have now been set and district wide multidisciplinary asthma care programmes instituted. This was followed by details from E. Massa and L. Corbetta of a district strategy from Italy involving collaboration between primary care and secondary care and the Italian Society of General Practitioners and the University of Ferrara, and they showed that implementation of spirometry in primary care was feasible as a diagnostic process in the management of airway disorders.

O. van Shayck clearly described experience from the Netherlands involving studies to identify barriers to good General Practitioner care and subsequent studies of education monitoring outcomes which included both health professional knowledge but also availability of equipment and patient quality of life. Interventions which involve confronting doctors with their own behaviour seemed to be a vital factor in success. Feedback on actual asthma care on a practice or on a patient level seems to have much more effect than even small group education, e.g. "In your prac- tice 1 out of 10 patients $(10 \%)$ smoke having not had smoking cessation advice, compared with 30 out of 128 patients $(23 \%)$ in the other practices" [9].

R. Neville continued the theme of feedback by describing his National Asthma Management study but drew attention to the fact that most published audits involved interested parties and that there was a low uptake of audit by nonasthma interested parties. In their studies primary care practices who employed nurses who had undertaken a diploma in asthma care did better than those who did not, and repeated audits were also associated with improved outcomes. R. Neville subsequently described systems already available in his service for electronic audit and outlined the potential for use of this service by others [1015].

In summary, meeting participants felt that the science behind successful implementation of asthma guidelines was strong and that after publication and dissemination of guidelines, should come implementation initiatives involving practice based interactive education, feedback, audit and continuous quality improvements. Most patients with asthma in Europe are now treated in primary care. Optimal implementation in primary care requires primary care involvement in working groups in GINA, EAACI and the ERS. Such specialist societies and organizations should consider setting up a pan European Task Force to assist the implementation of GINA guidelines in primary care, and interventions should be suitable for both developed countries and those which are less affluent. Such a Task Force is now being considered, and a follow-up GINA/ERS/EAACI meeting will take place in July 2000 in Lisbon (Spain), in conjunction with the Annual Meeting of the EAACI.

It is no good having guidelines on asthma if their existence does not benefit patients.

\section{References}

1. Warner JO, Gotz M, Landau LL, et al. Management of asthma: a consensus statement. Arch Dis Child 1989; 64: 1065-1079.

2. British Thoracic Society and others. The British Guidelines on Asthma Management 1995 Review and position statement. Thorax 1997; 52: S1-S2.

3. International Consensus report on the Diagnosis and Treatment of Asthma. National Heart, Lung and Blood Institute, National Institutes of Health, Bethesda, Maryland 20892, Publication No. 92-3091. Eur Respir J 1992; 5: 601-641.

4. National Heart, Lung and Blood Institute. Global strategy for asthma management and prevention. NHLBI Workshop Report. National Heart, Lung and Blood Institute 1995. NIH Publication No. 95; pp. 3659.

5. Doerschug KC, Peterson MW, Daytones L, Kline JN. Asthma Guidelines - an assessment of physician understanding and practice. Am J Respir Crit Care Med 1999; 159: $1735-1741$.

6. Partridge MR, Harrison BDW, Rudolf M, Bellamy D, Silverman M. The British Asthma Guidelines - their production, dissemination and implementation. Respir Med 1998; 92: 1046-1052.

7. Grimshaw JM, Russell IT. Achieving health gain through clinical guidelines. II. Ensuring guidelines change medical practice. Qual Health Care 1995; 3: 45-52. 
8. Clark NM, Gong M, Schork MA, et al. Impact of education for physicians on patient outcomes. Pediatrics 1998; 101: 831-836.

9. Smeel IJM, Grol RPTM, van Schayck CP, van den Bosch WJHM, van den Hoogen HJM, Muris JWM. Can small group education and peer review improve care for patients with asthma/chronic obstructive pulmonary disease? Qual Health Care 1999; 8: 92-98.

10. Hoskins G, Neville RG, Smith B, Clark RA. The link between practice nurse training and asthma outcomes. $\mathrm{Br}$ J Community Nursing 1999; 4: 222-228.

11. Hoskins G, Smith B, Neville RG, Clark RA. The Tayside Asthma Management Initiative. Health Bull (Edinb) 1998; 56: 586-591.
12. Hoskins G, Neville RG, Smith B, Clark RA. Does participation in distance learning and audit improve the acre of patients with acute asthma attack? Health Bull (Edinb) 1997; 55: 150-155.

13. Neville RG, Hoskins G, Smith B, Clark RA. How general practitioners manage acute asthma attacks. Thorax 1997; 52: $153-156$.

14. Neville RG, Hoskins G, Smith B, Clark RA. Observations on the structure, process and clinical outcomes of asthma care in general practice. Br J Gen Pract 1996; 46: 583587.

15. Neville RG, Clark RA, Hoskins G, Smith B, for general Practitioners in Asthma Group. National Asthma Attack Audit 1991-92. BMJ 1993; 306: 559-562. 